\title{
VALUE COMPONENT OF AMERICAN LANGUAGE GROUP CONSCIOUSNESS
}

\author{
Larisa O. Butakova \\ Omsk State University named after F.M. Dostoevsky, Omsk, Russian Federation \\ Svetlana Yu. Vyazigina \\ Omsk State Technical University, Omsk, Russian Federation
}

\begin{abstract}
The article presents the results of a free associative experiment. The purpose of the experiment was to determine the categorical components of the value system of the American ethnic group at the present stage. The associative fields obtained as a result of the experiment are analyzed by the authors using the method of lexical units semantic grouping within each field with the subsequent identification of the leading value categories of the value system. The results of these fields analysis allow to draw the following conclusions: the main value categories of the American ethnic group are (ranked in descending order of percentage): "Success", "Positivism", "Diligence", "Patriotism", "Individualism", "Family", "Religiousness". Private property is a basic component of American life, and individualism is a central organizing principle of interpersonal relations. The traditional value orientations "Family" and "Religiousness" do not occupy priority positions today. Stimuli related to politics, are evaluated ambivalently: in their associative fields there are groups of both positive reactions and groups with a large and average number of negative reactions (stimuli Revolution (as a political event), Constitution). This experiment is a part of a major study devoted to the comparison of value systems of Russian and American language groups.

Key words: association experiment, associative field, system of values, value orientation, ethno-cultural specificity.

Citation. Butakova L.O., Vyazigina S. Yu. Value Component of American Language Group Consciousness. Vestnik Volgogradskogo gosudarstvennogo universiteta. Seriya 2, Yazykoznanie [Science Journal of Volgograd State University. Linguistics], 2017, vol. 16, no. 2, pp. 99-108. (in Russian). DOI: https://doi.org/10.15688/ jvolsu2.2017.2.10.
\end{abstract}

\section{ЦЕННОСТНАЯ СОСТАВЛЯЮЩАЯ ЯЗЫКОВОГО СОЗНАНИЯ АМЕРИКАНЦЕВ}

\author{
Лариса Олеговна Бутакова \\ Омский государственный университет им. Ф.М. Достоевского, г. Омск, Российская Федерация
}

\section{Светлана Юрьевна Вязигина}

Омский государственный технический университет, г. Омск, Российская Федерация Аннотация. В статье представлены результаты свободного ассоциативного эксперимента, целью которо-
го было выявление категориальных составляющих системы ценностей американской этнической группы на
современном этапе развития социума. Полученные в результате эксперимента ассоциативные поля анализи-
руются авторами с применением метода семантической группировки лексических единиц в рамках каждого
поля с последующим выделением ведущих категорий ценностной системы. Результаты анализа полей позволя-
ют сделать следующие выводы: основными ценностными категориями американской этнической группы ста- 
ли (расположены по убыванию процентной представленности реакций): «Успех», «Позитивизм», «Трудолюбие», «Патриотизм», «Индивидуализм», «Семья», «Религиозность». Частная собственность является базовой составляющей жизни американцев, а индивидуализм - центральным организующим принципом межличностных отношений. Традиционные ценностные ориентиры «Семья» и «Религиозность» не занимают сегодня приоритетных позиций. Стимулы, в определенной степени относящиеся к политике, оцениваются амбивалентно: в их ассоциативных полях присутствуют как группы позитивных реакций, так и группы с большим и средним количеством негативных реакций (стимулы Revolution (как политическое событие), Constitution). Данный эксперимент является частью проводимого коллективом филологов масштабного исследования, посвященного сопоставлению систем ценностей русской и американской этнических групп.

Ключевые слова: ассоциативный эксперимент, ассоциативное поле, система ценностей, ценностные ориентации, этнокультурная специфика.

Цитирование. Бутакова Л. О., Вязигина С. Ю. Ценностная составляющая языкового сознания американцев // Вестник Волгоградского государственного университета. Серия 2, Языкознание. - 2017. - Т. 16, № 2. C. 99-108. - DOI: https://doi.org/10.15688/jvolsu2.2017.2.10.

1

Американская этническая группа, как и многие другие, формирует собственный тип культуры и, соответственно, характеризуется своими традициями, рядом культурных характеристик и сложившейся индивидуальной системой ценностей. Процесс формирования данной системы проходил под прямым воздействием ряда факторов, таких как географические особенности развития, приток иммигрантов и т. д. Однако особое влияние на формирование общественного сознания оказали идеи английских протестантов [Бельцова, 2013, с. 578]. Именно пуританизм, по мнению ряда исследователей (Л. Гринфилд, Т.Г. Голенпольский, В.П. Шестаков, О.В. Ладыка) стал идеологической базой, заложившей основы американской этики, морали и культурных традиций, определив идею особого пути развития американского общества [Попова, 2004, с. 19]. Таким образом, религиозный оптимизм, свойственный первым поселенцам, прибывшим в Новый Свет из старой Европы, заложил основу духовного образа современной Америки [Голенпольский, Шестаков, 1981, с. 18]. Считая себя группой «талантливых святых», «призванных самим Господом Богом», пилигримы позиционировали себя особыми людьми, пришедшими, чтобы «обладать этой землей» [Сардар, Дэвис, 2003, с. 115]. Именно осознание своей исключительности определило два базовых принципа концепта «Американская мечта» - признание своей избранности и понимание особой миссии Америки [Ладыка, 2014, с. 118].
В результате сложившийся американский национальный характер отражает особый склад мышления, психологии и поведения.

Цель нашего исследования - посредством анализа вербальных ассоциаций, полученных экспериментальным путем, выявить ценностные ориентации, отраженные в сознании американской этнической группы.

\section{2}

Для определения ценностных ориентаций данной этногруппы нами была применена наиболее разработанная и широко применяемая в современной психолингвистике методика ассоциативного эксперимента.

Ассоциативный эксперимент является одним из основных инструментов исследования субъективных семантических пространств индивида - полей слов, сформированных в сознании человека. Анализ этих полей позволяет вычленить этнолингвокультурную специфику восприятия индивидом базовых человеческих ценностей.

Для решения поставленной задачи из основных вариантов ассоциативного эксперимента (свободный, направленный, цепочный) нами была выбрана методика свободного ассоциативного эксперимента, не ограничивающая реципиентов в выборе словесных реакций. В процессе проведения массового свободного ассоциативного эксперимента англоговорящим испытуемым был предложен список слов-стимулов. На каждое слово требовалось отреагировать с помощью языковой единицы или фразы, описывающей возникший 
в сознании образ. Согласно традиции проведения свободного ассоциативного эксперимента испытуемые не ограничивались рамками определенного грамматического класса.

Перед проведением эксперимента реципиенты заполняли анкету, в которой требовалось указать пол, возраст и родной язык, далее следовала инструкция к выполнению задания и 30 слов-стимулов, разделенных на 6 смысловых кластеров.

Первый кластер представлен словами me, human, think, good, bad, входящими в ядро ментального лексикона, выделенного А.А. Залевской в процессе исследований, проведенных на материале «The Associative Thesaurus of English» [Залевская, 2005, с. 111].

Второй кластер включает слова house, family, work, time, money, номинирующие базовые общечеловеческие ценности. Предполагается, что указанные ценностные категории имеют различия в ценностных ориентациях, то есть в восприятии и понимании данных ценностей.

Третий кластер составили интернационализмы: revolution, president, businessman, Internet, constitution - слова, совпадающие во многих языках по своей внешней форме и полностью или частично совпадающие по значению. Использование таких слов в эксперименте обусловлено тем, что усилившийся за последнее десятилетие процесс глобализации не мог не отразиться на словарном составе языков и сознании их носителей.

В четвертый кластер вошли слова, номинирующие собой общие понятия в любой культуре: documents, transport, travelling, science, clothes. Исследование ассоциативного восприятия данных слов должно, на наш взгляд, продемонстрировать восприятие и частных составляющих данных понятий, что позволит охватить максимально широко диапазон ценностных ориентаций носителей американской культуры.

Следует отметить, что проведенный нами эксперимент является частью исследования, предполагающего сопоставление ценностных картин мира разных этнических групп (американской, русской и др.). В связи с этим в пятый и шестой кластеры вошли этноориентированные слова, имеющие специфическую культурно-историческую окраску: пятый кла- стер (русские реалии) включает слова vinaigrette, balalaika, matryoshka, blini, samovar; шестой кластер (американские реалии) включает слова weekend, hot-dog, muffin, whisky, ale.

Экспериментальное исследование проводилось в апреле - сентябре 2015 года. Из полученных 158 анкет было отобрано для дальнейшего анализа 130, каждая из которых содержала 30 вербальных реакций на 30 словстимулов. Английский язык был указан реципиентами как родной язык.

Полученные 3900 реакций были объединены в семантические группы в рамках каждого стимула. Все полученные на каждый стимул реакции ранжировались по степени частотности и позволили сконструировать ассоциативное поле каждого стимула, являющееся отражением сознания данной этнической группы.

3

По результатам проведенного эксперимента нами были выделены следующие ценностные ориентиры американской этнической группы.

3.1. Стремление к успеху является одной из основных особенностей американцев. Семантические поля большинства стимулов включают реакции, соотносящиеся с данной ценностной категорией, что подчеркивает целеустремленность, работоспособность и ориентацию на достижение различных социальных и материальных благ американцев. Например, в ядре стимула $M е$ содержатся реакции prosperous (2), successful (1), established (1). Процесс мышления воспринимается американцами как направленный на результат, что подтверждается реакциями, входящими в ядро стимула Think: arriving at satisfaction (2), solutions (2), solve problems (2). В ассоциативном поле стимула Good также выделяется группа реакций, соотносящихся с данной ценностной категорией: «хороший», по мнению американцев, - это выгодный profitable (2), поэтому работа work (2) должна быть хорошая, то есть приносящая деньги - money (1).

Образ дома представлен в ассоциативном поле стимула House с точки зрения пре- 
стижа. Группа из 90 реакций отражает детальное описание данного объекта: home (26), roof (19), garden (17) и т. д. Такое отношение продиктовано, с одной стороны, ценностным отношением к институту семьи и родного дома как частной составляющей данного понятия, а с другой - важностью владения частной собственностью, определяющей статус человека в западной культуре.

Уровень заработка является главным показателем успешности человека. Поэтому работа, по мнению американской этнической группы, должна быть престижной prestigious (2) и финансово привлекательной money (26), means of earning a living (1), pay (1), на что указывают реакции ассоциативного поля стимула Work.

Особую ценность для современного американца представляет время. С этой позиции успешный человек, по мнению данной этногруппы, должен уметь грамотно распределять свое время. Такое отношение можно проследить, анализируя ассоциативное поле стимула Time, в котором реакция management (10) является одной из наиболее многочисленных.

Критерии успешности ярко представлены в ассоциативном поле Businessman. Внешний вид человека во многом определяет его успешность. Например, наиболее повторяющейся реакцией ассоциативного поля данного стимула является реакция suit and tie (15). Семантически связаны с этими атрибутами реакции suit (14), suitcase (5), man in suit (4), black suit (1). Успешный в бизнесе человек проницателен - achiever (3), сообразителен acumen (4) и амбициозен - ambition (3). Ценностное отношение к финансовому состоянию также отмечается на примере данного ассоциативного поля: реакции тоney (8) и man who exchanges time for money (1) подтверждают важность данной категории для американской этнической группы.

Особой ценностью представляется наука - important (1), она является залогом успеха - success (3) и развития - progress (2).

3.2. Американский патриотизм является базовой составляющей всей ценностной системы американского общества. В нашем исследовании данная категория проявилась в ряде стимулов.
Например, стимул $M e$ в ядре своего ассоциативного поля содержит реакции American (4) и Yankee (2). Данные реакции, входящие в ядро ассоциативного поля предложенного стимула, указывают на то, что восприятие себя частью данного государства представляет особую гордость для ее граждан.

При восприятии стимула Good реципиентами в качестве реакции были даны названия американских брендов. Так, «хорошими», по мнению реципиентов, могут быть продукция американской корпорации «Apple» (2), автомашины американской автомобильной компании «Chrysler» (2) и сеть дорогих американских отелей и ресторанов «Essex House» (1).

В ассоциативном поле стимула House находятся реакции, представляющие собой географические названия городов и штатов Америки: Washington (3), Ohio (2), New York (1).

Некоторые реакции стимула Work являются наименованиями престижных американских компаний: «JP Morgan Chase» (1), «General Electric» (1), «Abbott» (1). Сама же работа, по мнению реципиентов, должна быть престижной prestigious (2).

Только с американской валютой ассоциируются у реципиентов деньги. Так, ассоциативное поле стимула Money включает 55 реакций, называющих данное понятие: dollars (22), dollar bills (20), green (12), dollar sign (1).

Исторические события, происходившие в родной стране, отразились в реакциях стимула Revolution: American revolution (4), Franklin (2), Benjamin Franklin (1), 1765 (1). Однако следует отметить, что наиболее многочисленной реакцией данного ассоциативного поля является реакция France (29).

Наиболее широко тема патриотизма представлена в ассоциативном поле стимула President. Ассоциативное поле стимула содержит 103 реакции, непосредственно связанные с историей США, 37 из которых соотносятся с названием страны: USA (32), the US (3), states (2), а 56 реакций называют имена американских президентов: Barack Obama (23), Johnson (17) и Kennedy (13). Значительно меньшим количеством представлены реакции Bill Clinton (1), Eisenhower (1) и Nixon (1).

В ядре стимула Constitution содержатся реакции, называющие реалии политической 
жизни США, что указывает на патриотическое отношение к родной стране. Наиболее многочисленная ассоциация - здание конгресса США: Capitol Hill (5). Связь с родной страной также является важной составляющей сознания, что выражается реакциями America (2), USA (2). К немногочисленным реакциям этого поля относятся: исторически важный документ bill of rights (1) и реакция, называющая группу важных политических деятелей, сыгравших ключевую роль в становлении американской государственности, так называемых отцов-основателей - founding fathers (1).

При восприятии стимула Transport в сознании американских респондентов возникли ассоциации, связанные прежде всего с национальными марками машин: «Ford» (3), «Jeep» (1), «Dodge» (1). Среди реакций данного ассоциативного поля только одна обозначает иностранную марку машин «Ferrari»(1).

Образование, наука и новые технологии играют важную роль в жизни современных американцев. Так, в качестве реакций на стимул Science реципиентами были названы только университеты Америки: Berkley (4), Harvard University (1), Yale (1).

Одежда американцев - это прежде всего Jeans (4) или jeans and tank top (1) и «Prada» (2). Указаны также американские бренды «Smithy's» (1) и «Nike» (1).

Ассоциативные поля стимулов, входящих в кластер слов, называющих американские реалии, не содержат отказов, что свидетельствует о важности представленных единиц для американской группы реципиентов. Напротив, стимулы, относящиеся к кластеру русских этноориентированных слов, содержат в ассоциативных полях большое количество отказов, выраженных в виде прочерков или пропусков строки.

3.3. Религиозные, в частности пуританские, идеи церкви оказали прямое воздействие на формирование национального характера и мировоззрения современных американцев. Энциклопедический словарь «Америка. Энциклопедия повседневной жизни» приводит данные, согласно которым процент верующих (93 \%) в США является самым высоким в западном мире [Америка..., 1998, с. 27]. По мнению ученых, это объясняется тем, что совре- менная цивилизация США формировалась на той культурно-исторической стадии, когда еще преобладал религиозный тип сознания [Танасейчук, 2009, с. 107].

В связи с этим при анализе системы американских ценностей необходимо было учитывать религиозные убеждения, оказавшие значительное влияние на формирование общенациональных ценностей американского общества.

Ассоциативные поля некоторых стимулов включают реакции или группы реакций, относящиеся к религиозной тематике. В качестве примера можем привести реакцию divine (1) («религиозный, богоподобный, божественный»), находящуюся в ассоциативном поле стимула $M e$.

Однако особенно ярко религиозность американцев проявилась в ассоциативном поле стимула Human. Ядро ассоциативного поля данного стимула содержит многократно повторяющуюся реакцию $\operatorname{God}(8)$, напрямую ассоциирующую человека с богом. В указанном ассоциативном поле содержится также единичная реакция painting of Adam and God in Sistine Chapel (1).

Оттенки религиозных смыслов присутствуют в реакциях на стимул Think: процесс мышления воспринимается реципиентами как духовно-религиозная практика-meditation (11) или meditate (1), а также believe (1).

Стимул Good вызывает в сознании американской группы реципиентов реакции, связанные с Богом. Имя Бога $(G o d)$ упоминается девять раз и, таким образом, входит в ядро ассоциативного поля данного стимула. Реакция evil (2) в значении «порок» или «грех» также входит в ядро указанного ассоциативного поля. В нем присутствует и реакция halo «нимб».

Одной из наиболее многочисленных реакций ассоциативного поля стимула $\mathrm{Bad}$ является реакция evil (25) («порок», «грех»), а также отмечаются единичные реакции God (1) и Devil (1).

Среди лексических единиц, номинирующих реалии американской жизни, стимул Weekend вызвал только одну ассоциацию, связанную с религией, - Period of rest from work and worship god (1).

Ассоциативное поле стимула Whisky coдержит единичную реакцию priest (1). 
3.4. Особую роль в американском обществе играет семья. Оказывая влияние на каждую личность индивидуально и на общество в целом, семья является важнейшим социальным институтом, представляющим ценностную категорию современного американского общества, что подтверждается большим количеством реакций, тематически связанных с понятием «семья». Однако, несмотря на то, что семья считается в американском социуме традиционной ценностью, отношение современных американцев к ней с течением времени трансформируется. Так, ассоциативное поле стимула $M e$ включает реакции, соотносящие респондентов с их домом и различными членами семьи: home (1), My Facebook picture (picture of my wife and me at a wedding) (1), wife (1). Однако такие реакции единичны, в то время как ядро ассоциативного поля данного стимула содержит реакцию alone (9).

Чувство одиночества у современных американцев выражается в особо трепетном отношении к животным, близость с которыми является значимой составляющей их жизни: например, зафиксирована реакция на стимул Good - girl (my dog Daisy, "she's good girl!”) (1), однако подобные ей реакции, связанные с семьей и ее членами, отсутствуют. В ядре ассоциативного поля стимула House одной из самых многочисленных является реакция family (20), при этом большую смысловую нагрузку имеет реакция $\operatorname{dog}(5)$, находящаяся в ядре того же стимула.

Образ семьи детально отражен в ядре ассоциативного поля стимула Human. Человек (Human) ассоциируется прежде всего с мужем и в меньшей степени - с отцом или женихом: husband (5), dad (2), fiancé (1).

Особого внимания заслуживает ассоциативное поле стимула Family. В данном поле выделена группа, состоящая из 36 реакций, смысловое содержание которой полно характеризует традиционный образ семьи. Возможно, такой результат связан с принадлежностью респондентов к штату Огайо, население которого отличается консервативностью в отношении к базовым семейным ценностям на фоне трансформации ценностных ориентаций в США сегодня. Таким образом, семья - это прежде всего родители: parents (14), mother (2), mom (1), dad (1), father (1) и дети: children (5), kids (3), baby (1). Следует указать на особый вес реакции friends (9), свидетельствующий о значимости данной реалии в семейной жизни американцев.

Для американской семьи важна материальная сторона жизни, что выражено реакцией business (11), находящейся в ядре ассоциативного поля данного стимула. Одной из определяющих особенностей семейной жизни американца является собственный дом, что подтверждается множественной реакцией home (20), а также house (2), находящимися в ядре ассоциативного поля стимула Family.

Следует отметить, что в ядре ассоциативного поля данного стимула отсутствуют лексические единицы, обозначающие чувства, возникающие между родственниками. Исключением являются такие единичные реакции ассоциативного поля, как love (1), cherish (1), happiness (1). В большей степени выражена прагматическая оценка взаимоотношений в семье: home (21), business (11), house (2), law (6), doctor (2), genetic or emotional kin (1).

Семья воспринимается как closely knit group of persons (1), circle (1), people huddled close (1), такие реакции отражают образность мышления американской группы реципиентов.

Выходные дни у американцев связаны с родным домом и семьей, что отражено в ассоциативном поле стимула Weekend: home (3), family (1), laundry (1), mowing grass (1).

Следует отметить особую роль друзей в жизни современных американцев. Реакция friends (9) является одной из самых многочисленных в ядре ассоциативного поля стимула Family и третьей по частотности (11) в ядре ассоциативного поля стимула Weekend. При этом реакция family единична в данном ассоциативном поле. По-видимому, все это свидетельствует об отчужденности во внутрисемейных отношениях опрашиваемой этнической группы.

Итак, анализ ассоциативного поля стимула Family позволяет трактовать образ ценностной категории «Семья» в традиционной его форме, несмотря на современные социальные процессы, влияющие на американское общество.

3.5. В ассоциативном пространстве нашего эксперимента содержится большое количество реакций, подчеркивающих чувства 
независимости, самодостаточности, указывающих на четкую границу между общественной и частной жизнью. Таким образом, частная собственность является базовой составляющей жизни американцев, а индивидуализм - центральным организующим принципом межличностных отношений и одной из основных ценностей американской этнической группы.

Ассоциативное поле стимула $M е$ содержит группу из 55 реакций, большая часть которых находится в ядре данного ассоциативного поля: I (22), myself (10), alone(9), me (8), person (3).

Стимул Work вызывает у реципиентов ассоциации со своей работой: my office (5), my business-office (1), my office area (1).

Президент страны для американцев это, прежде всего, человек с лидерскими качествами - leader (4), являющийся самостоятельной личностью - individual person (1).

Данная ценностная категория представлена в ассоциативном поле стимула Businessman. Так, деловой человек характеризуется реакциями achiever (3), ambition (3), me (2), myself (1), а также who follows his dream (1).

Конституция для американцев является гарантом сохранности личных прав и частной собственности, что подтверждается такими реакциями, входящими в ядро ассоциативного поля Constitution, как rights (11), private property (2), private law (2), individual rights (1).

Предпочтение, отданное индивидуальному транспортному средству, а не общественному транспорту, показательно и выражено в реакциях ассоциативного поля Transport: наиболее частотна реакция $\operatorname{car}(33)$, большой вес имеет и реакция bike (18).

Стимулы Whisky, Ale в своих ассоциативных полях содержат реакции, указывающие на индивидуальные предпочтения реципиентов в отношении алкоголя. Так, в отношении стимула Whisky реципиенты предложили большое количество реакций, называющих другие напитки: gin (25), scotch (14), beer (1). В accoциативных полях обоих напитков содержались реакции, прямо указывающие на индивидуальное отношение испытуемых к этому напитку: vodka's better (1), yikes (1), yummy (1) и т. д.
3.6. Следует отметить еще одну важную характеристику, выделенную в рамках нашего эксперимента, - отношение американцев к труду. Данная категория характеризуется не столь многочисленными реакциями, как описанные выше. Однако ассоциативные поля практически всех стимулов содержат небольшое количество реакций, подчеркивающих положительное отношение представителей данной культуры к труду и созидательной деятельности.

Наиболее ярким примером являются ассоциации hardworking (3), входящая в ядро ассоциативного поля стимула Human, и work (2), входящая в ассоциативное поле стимула Good, которые подчеркивают положительное отношение к трудовой деятельности представителей данной группы. Ленивый человек считается «плохим», что подтверждается реакцией lazy (16), находящейся в ядре ассоциативного поля Bad.

Положительная оценка труда подтверждается на примере стимула Family, в ядре acсоциативного поля которого находится многочисленная реакция business (11).

Стимул Work, помимо реакций, выражающих положительное отношение к объекту, названному словом-стимулом, содержит группу реакций, детально описывающую рабочую обстановку реципиентов: computer (29), desk (18), business-office (1), day (1), desk and computer (1), manual (1), my office area (1), weekdays (1), professional setting (1).

Ассоциативное поле стимула Businessman не содержит отрицательных по значению реакций. В целом трудолюбие американцев на примере данного стимула наилучшим образом характеризуется группой слов, называющих качества современного бизнесмена: это человек дальновидный, стремящийся достичь своих целей, трудолюбивый и энергичный: acumen (4), ambition (3), achiever (3), hurry (1) и т. д.

Интернет служит в равной степени как для различного рода развлечений, так и для работы. С одной стороны, это важный элемент современного общения: communication (13), Facebook (7), friends (4), communication with people (2). С другой стороны, это не менее важная платформа для работы: work (9), data (8), programmer (7), programming (3), 
datum (1), subsidiary (1). Эти тематические группы, выделенные в ассоциативном поле стимула Internet, равнозначны по количеству реакций.

Наибольшее количество ассоциативных реакций, связанных с работой, вызвал стимул Documents. В общей сложности зафиксировано 117 реакций, большая часть которых входит в ядро ассоциативного поля данного стимула; наиболее частотны из них paper (53) и work (16).

3.7. Ценностной ориентацией для американцев является позитивное отношение к жизни. Следует обратить внимание на контраст позитивных и негативных реакций в ассоциативных полях всех предложенных стимулов. Например, восприятие себя, отраженное в ассоциативном поле стимула $M e$, представлено как позитивное через реакции funny (6), person (3), friendly (1), happy (1), kind (1), lovely (1), большая часть которых входит в ядро ассоциативного поля. Негативных реакций, представленных в данном поле, значительно меньше: bad (5), awesome (1), confused (1), tired (1).

Оптимизм американцев проявляется в процессе мышления. Думать следует только в позитивном направлении, о чем свидетельствует множественная реакция positive (7) в ядре ассоциативного поля стимула Think. Peакции, выражающие противоположную оценку, в указанном поле единичны: better (1), no (1), nothing (1).

Стимул Good вызвал как позитивные, так и негативные реакции. К группе позитивных реакций были отнесены fine (22), nice (20), smiling faces (4), happy (2), heart (2), fun (1), smiles (1), individuals smiling (1). Группа негативных реакций представлена в большей степени антонимической реакцией bad (37), а также не столь множественной реакцией evil (2).

Для данной этнической группы даже «плохое» иногда может быть «хорошим». Так, одной из единичных реакций ассоциативного поля стимула $\mathrm{Bad}$ является реакция sometimes can be good (1), а самой множественной реакцией ядра - антонимическая реакция good (34).

Ассоциативное поле стимула House coдержит положительные реакции, выраженные в сенсорном восприятии данного стимула: warm building (1), warms (1). Негативные peакции в ассоциативном поле данного стимула не отмечены.

Ассоциативное поле стимула Work coдержит две сопоставимые по количеству реакций группы. Так, работа должна быть интеpeсной - interesting (5), энергичной - energy (1) и дающей возможности - opportunity (1). Если она не отвечает указанным требования, она расценивается как death (1), headache (1), no (1), stress (1), tedious (1).

В ассоциативном поле стимул Businessman не было отмечено негативных реакций: деловой человек, имеющий свой бизнес, ассоциируется с успехом - success (7) и удовольствием - pleasure (1).

Неоднозначное отношение вызвал стимул Internet. С одной стороны, по мнению реципиентов, глобальная сеть есть необходимая - necessary (1) составляющая их жизни life (3). С другой стороны, Интернет - это зло - evil (3).

Следует отметить тот факт, что стимулы, в определенной степени относящиеся к политике, содержат в своих ассоциативных полях группы с большим количеством негативных реакций. Например, стимул Revolution (как политическое событие) вызывает у реципиентов негативные эмоции, что подтверждается наличием группы следующих реакций: death (1), bloody (1), bad (1), stupidity (1), mad (1), trouble (1).

Несмотря на патриотическое отношение американцев к своей стране и, в частности, к президенту США, представлены единичные негативные реакции в ассоциативном поле стимула President: dead (1), corruptdemocracy (1).

Конституция страны, по мнению реципиентов, является важным - important (1) документом, но в то же время определенная степень недовольства проявляется на примере группы реакций bosh (1), bullshit (1), constipation (1), corruption (1), drag (1), mess (1), powerful words on paper (1), rag (1).

Наибольшее количество позитивных реакций, по сравнению с другими стимулами, вызвал Weekend. Общая сумма реакций данной группы составила 37.

Таким образом, анализ результатов проведенного ассоциативного эксперимента по- 
зволяет выявить особенности современных ценностных ориентаций американской этнической группы.

\section{4}

Итак, на основании частотности повторения сгруппированных по семантическому принципу реакций, повторяющихся в большинстве стимулов, мы выделили ключевые понятия ценностной системы американской этнической группы.

Исходя из полученных данных, основной ценностной категорией американской этнической группы стала ценностная категория «Успех». В данную группу вошло 489 реакций, что составило 9,8 \% от общего числа ассоциативных реакций.

Ценностный ориентир «Позитивизм» также является важной составляющей сознания представителей данной этнической группы. Группа включает 424 реакции, что составляет $10,8 \%$ от общего числа ассоциативных реакций.

Свойственное американцам «Трудолюбие» характеризуется 295 реакциями, или $7,5 \%$ от общего числа всех ассоциативных реакций.

«Патриотизм» как неотъемлемая составляющая американского общества представлен в группе из 264 реакций, что составляет $6,76 \%$ от общего числа ассоциативных реакций.

Одной из ключевых черт американского общества является индивидуализм. Данная группа включает 104 реакции, что составляет $2,7 \%$ от общего числа реакций.

Традиционные ценностные ориентиры «Семья» и «Религиозность» не занимают сегодня приоритетных позиций. На стимул Family было дано 137 реакций, что составляет $3,5 \%$ от общего числа ассоциаций, на стимул $G o d-79$, или только $2 \%$ от общего числа реакций.

\section{СПИСОК ЛИТЕРАТУРЫ}

Америка. Энциклопедия повседневной жизни / общ. ред. Л. М. Гейман. - М. : Энциклопедическая Творческая Ассоциация, 1998. - 416 с.
Бельцова, И. А. Ценностные приоритеты и образ успешного человека в культуре и СМИ США / И. А. Бельцова // Молодой ученый. 2013. - № 10 (57), ч. 4. - С. 578-583.

Голенпольский, Т. Г. «Американская мечта» и «американская действительность / Т. Г. Голенпольский, В. П. Шестаков. - М. : Искусство, 1981. $208 \mathrm{c}$.

Залевская, А. А. Психолингвистические исследования. Слово. Текст : избр. тр. / А. А. Залевская. - М. : Гнозис, 2005. -543 с.

Ладыка, О. В. Американский национальный характер и его интерпретация в работах лингвистов / О. В. Ладыка // Новый взгляд. Международный научный вестник : сб. науч. тр. / под общ. ред. С. С. Чернова. - Новосибирск : Изд-во ЦРНС, 2014. Вып. 4. - С. 114-123.

Попова, М. К. Национальная идентичность и ее отражение в художественном сознании / М. К. Попова. - Воронеж : Воронеж. гос. ун-т, 2004. $-170 \mathrm{c}$.

Сардар, 3. Почему люди ненавидят Америку? 13. Сардар, М. В. Дэвис. - М. : Проспект, 2003.-240 с.

Танасейчук, А. Б. Культурно-исторический тип американской цивилизации и его особенности / А. Б. Танасейчук // Вестник Томского государственного университета. - 2009. - № 318. - С. 106-109.

\section{REFERENCES}

Geyman L.M., ed. Amerika. Entsiklopediya povsednevnoy zhizni [America. Encyclopedia of Everyday Life]. Moscow, Entsiklopedicheskaya Tvorcheskaya Assotsiatsiya Publ., 1998. 416 p.

Beltsova I.A. Tsennostnye prioritety i obraz uspeshnogo cheloveka v kulture i SMI SShA [Value Priorities and the Image of a Prosperous Person in the USA Culture and Media]. Molodoy uchenyy, 2013, no. 10 (57), part 4, pp. 578-583.

GolenpolskiyT.G., Shestakov V.P. «Amerikanskaya mechta» $i$ «amerikanskaya deystvitelnost» ["American Dream" and "American Reality"]. Moscow, Iskusstvo Publ., 1981. 208 p.

Zalevskaya A.A. Psikholingvisticheskie issledovaniya. Slovo. Tekst : izbr. tr. [Psycholinguistic Research. Word. Text: Selected Works]. Moscow, Gnozis Publ., 2005. 543 p.

Ladyka O.V. Amerikanskiy natsionalnyy kharakter $\mathrm{i}$ ego interpretatsiya $\mathrm{v}$ rabotakh lingvistov [American National Character and Its Interpretation in Linguistic Works]. Chernov S.S., ed. Novyy vzglyad. Mezhdunarodnyy nauchnyy vestnik: sb. nauch. tr. [A New Look. International Scientific Bulletin: Collection of Scientific Papers]. Novosibirsk, Izd-vo CRNS, 2014, iss. 4, pp. 114-123. 


\section{ГЛАВНАЯ ТЕМА НОМЕРА}

Popova M.K. Natsionalnaya identichnost $i$ ee otrazhenie $v$ khudozhestvennom soznanii [National Identity and Its Reflection in Art Consciousness]. Voronezh, Voronezh. gos. un-t Publ., 2004. 170 p.

Sardar Z., Djevis M.V. Pochemu lyudi nenavidyat Ameriku? [Why Do People Hate America?]. Moscow, Prospekt Publ., 2003. 240 p.
Tanaseychuk A.B. Kulturno-istoricheskiy tip amerikanskoy tsivilizatsii i ego osobennosti [Cultural and Historical Type of American Civilization and Its Peculiarities]. Vestnik Tomskogo gosudarstvennogo universiteta, 2009, no. 318, pp. 106-109.

\section{Information About the Authors}

Larisa O. Butakova, Doctor of Sciences (Philology), Professor, Head of Department of Russian, Slavic and Classical Linguistics, Omsk State University named after F.M. Dostoevsky, Prosp. Mira, 55a, 644043 Omsk, Russian Federation, larisabut@rambler.ru, http://orcid.org/0000-0003-3210-2311.

Svetlana Yu. Vyazigina, Lecturer, Department of Foreign Language, Omsk State Technical University, Prosp. Mira, 11, 644050 Omsk, Russian Federation, viazigina_s@mail.ru, http://orcid.org/ 0000-0003-1740-424X.

\section{Информация об авторах}

Лариса Олеговна Бутакова, доктор филологических наук, профессор, заведующая кафедрой русского языка, славянского и классического языкознания, Омский государственный университет им. Ф.М. Достоевского, просп. Мира, 55a, 644043 г. Омск, Российская Федерация, larisabut@rambler.ru, http://orcid.org/0000-0003-3210-2311.

Светлана Юрьевна Вязигина, преподаватель кафедры иностранных языков, Омский государственный технический университет, просп. Мира, 11, 644050 г. Омск, Российская Федерация, viazigina_s@mail.ru, http://orcid.org/0000-0003-1740-424X. 